\title{
Health Lens Analysis: A Strategy to Engage Community in Environmental Health Research in Action
}

\author{
Sharon Ron ${ }^{1, *}{ }^{\circ}$, Noelle Dimitri ${ }^{2}{ }^{\circ}$, Shir Lerman Ginzburg ${ }^{3}$, Ellin Reisner ${ }^{4}$, Pilar Botana Martinez ${ }^{5}$, \\ Wig Zamore ${ }^{4}$, Ben Echevarria ${ }^{6}$, Doug Brugge ${ }^{7}{ }^{\circ}$ and Linda S. Sprague Martinez ${ }^{8}$
}

\section{check for}

updates

Citation: Ron, S.; Dimitri, N.; Lerman Ginzburg, S.; Reisner, E.; Botana Martinez, P.; Zamore, W.; Echevarria, B.; Brugge, D.; Sprague Martinez, L.S. Health Lens Analysis: A Strategy to Engage Community in Environmental Health Research in Action. Sustainability 2021, 13, 1748. https://doi.org/10.3390/su13041748

Academic Editors: Mihajlo (Michael) Jakovljevic and Fernando Brandão Alves

Received: 14 December 2020

Accepted: 1 February 2021

Published: 6 February 2021

Publisher's Note: MDPI stays neutral with regard to jurisdictional claims in published maps and institutional affiliations.

Copyright: (c) 2021 by the authors. Licensee MDPI, Basel, Switzerland. This article is an open access article distributed under the terms and conditions of the Creative Commons Attribution (CC BY) license (https:/ / creativecommons.org/licenses/by/ $4.0 /)$.
1 Metropolitan Area Planning Council, 60 Temple Place, Boston, MA 02111, USA

2 School of Social Work, Boston University, 264 Bay State Rd., Boston, MA 02215, USA; noelled@bu.edu

3 Department of Public Health Sciences, UConn Health, Farmington, CT 06032, USA; sginzburg@uchc.edu

4 Somerville Transportation Equity Partnership, Somerville, MA 02145, USA; reisnere51@gmail.com (E.R.); wigzamore@gmail.com (W.Z.)

5 Department of Environmental Health, Boston University School of Public Health, 715 Albany Ave., Boston, MA 02118, USA; pbotana@bu.edu

6 The Welcome Project, 530 Mystic Ave., Somerville, MA 02145, USA; ben@welcomeproject.org

7 Department of Public Health Sciences, University of Connecticut School of Medicine, 263 Farmington Ave., Farmington, CT 06030, USA; brugge@uchc.edu

8 Macro Department, School of Social Work, Boston University, 264 Bay State Rd., Boston, MA 02215, USA; lsmarti@bu.edu

* Correspondence: SRon@mapc.org

\begin{abstract}
Health Lens Analysis (HLA) is a tool to facilitate collaboration among diverse community stakeholders. We employed HLA as part of a community-based participatory research (CBPR) and action study to mitigate the negative health effects of traffic-related air pollution TRAP and ultrafine particles (UFPs) in Somerville, MA. HLA is a Health in All Policies tool with previously limited implementation in a North American context. As part of the HLA, community and academic partners engaged residents from across near-highway neighborhoods in a series of activities designed to identify health concerns and generate recommendations for policies and projects to improve health over an 18-month planning period. Noise barriers, which may reduce TRAP exposure among residents in addition to reducing traffic noise, were seen as an acceptable solution by community stakeholders. We found HLA to be an effective means to engage stakeholders from across sectors and diverse community residents in critical discourse about the health impacts of near-roadway exposures. The iterative process allowed the project team to fully explore the arguments for noise barriers and preferred health interventions, while building a stakeholder base interested in the mitigation of TRAP, thus creating a shared language and understanding of the issue.
\end{abstract}

Keywords: health lens analysis; traffic-related air pollution; community engagement; resident-driven design; health in all policies; noise barriers; social determinants of health; community planning

\section{Introduction}

An increasing focus on the importance of the social determinants of health has led to interest in public health strategies designed to foster a broad understanding of individual health and the ways in which it is influenced by environmental context. The built environment and the social context which surrounds it rarely falls under the purview of public health. Therefore, local health authorities and public planners have turned to a health in all policies (HiAP) framework to better understand this relationship as well as encourage multisectoral partnerships [1,2].

Health in All Policies (HiAP) is a World Health Organization (WHO) framework employing interdepartmental and cross-sector collaboration to ensure an integrated policymaking lens. HiAP addresses the health impact of a given policy, thereby improving the environmental conditions that promote the health of communities [3]. The use of HiAP is 
increasingly widespread and endorsed by the Pan American Health Organization (PAHO), and the American Public Health Association (APHA), in addition to the WHO. It has also been adopted in settings ranging from a statewide initiative in California to the Finnish health policy strategy [3-6]. Essential to HiAP is the ability to link health outcomes to governmental projects and policies. Tools associated with HiAP, such as Health Lens Analysis (HLA), have emerged to provide processes for gathering evidence, engaging multiple sectors of community life, and generating health-based recommendations [7].

As part of a research and action study designed to mitigate transportation-related air pollution (TRAP), we sought to employ Health Lens Analysis (HLA) in an effort to inform land use and transportation policies beneficial to health. HLA is a methodology designed to facilitate collaboration among diverse community stakeholders including residents, public health practitioners, planners and government agency staff working on projects which have implications for health and well-being [7]. HLA was developed by the Government of South Australia as part of their HiAP strategy, where it was used to inform planning and policy efforts on a wide variety of topics [7], such as an HLA project to develop parental engagement strategies for improved childhood literacy skills [8]. Although adoption of HLA has been limited outside of South Australia, HLA has been an effective method to facilitate collaboration among governmental sectors in South Australia aimed at improving population health $[9,10]$.

HLA can be applied across many conditions and by multiple actors, making it relevant for a range of health initiatives. For example, in 2017, the Massachusetts Area Planning Council (MAPC) used HLA to examine how an urban agriculture policy could be implemented in ways that promote health and promote equitable engagement in urban agriculture [11]. This led to the publication of an accessible urban agriculture resource guide [12] and a better understanding of urban agriculture amongst local government officials and community leaders.

To date, the literature on HLA is limited. We still do not fully understand best practices. This is particularly true with respect to how community stakeholders might employ HLA to inform local polices in an effort to improve community conditions. As such, we present an illustrative description of the process of implementing an HLA focused on TransportationRelated Air Pollution (TRAP), in an effort to build the HLA literature as well as local public health planning efforts that seek to infuse a health lens on local decision-making. In our case, community stakeholders sought to translate research related to the impact of TRAP on community health by informing local decision-making, policy and practice. We provide a brief background on HLA and our project, followed by a detailed description of our HLA process. HLA outcomes to date and lessons learned are then presented.

\section{Background}

The HLA process requires all sectors to adopt a shared definition of health as "a state of complete physical, mental and social wellbeing and not merely the absence of disease or infirmity" in order to work collaboratively to consider the health and equity impacts of all policies and practices [7]. Multisectoral partnerships can help communities create the conditions that enable health-promoting activities by allowing stakeholders from divergent interests to coalesce around a shared goal [1,2]. The HLA process is a systematic methodology that can be used to facilitate collaboration among community and health sector representatives, and government agencies on projects focused on health and well-being.

The objective of an HLA is to inform the drafting or revision of policy and to influence policy implementation that affects community health [13]. Similar to the Health Impact Assessment (HIA), HLA uses a systematic process, which includes data collection, analytic methods, and stakeholder input to evaluate the potential positive and negative public health effects of a specific plan, project or policy [14]. In contrast to HLA, HIA also provides decision-makers with recommendations for monitoring and managing those effects $[7,8]$. Despite this difference, many HIA and HLA principles, techniques and strategies are 
similar [8,9]. Both employ a structured, stepwise process for assessing health implications and are rooted in an underlying belief in the value of collaboration to achieve sustainable change in population health outcomes [15]. Table 1 outlines the conditions of use associated with both HLA and HIA, as well as the steps for their implementation. For our purposes, the primary difference between these two tools is the rationale behind the approach. HLA does not require a specific proposal, in contrast to the HIA process. Thus, HLA allows health considerations to inform policy at the conceptual stage.

Table 1. A Comparison of HLA and HIA Steps and Conditions for Use.

\begin{tabular}{|c|c|c|}
\hline & HLA & HIA \\
\hline Steps & $\begin{array}{ll}\text { 1. } & \text { Engage } \\
\text { 2. } & \text { Gather Evidence } \\
\text { 3. } & \text { Generate } \\
\text { 4. } & \text { Navigate } \\
\text { 5. } & \text { Evaluate }\end{array}$ & $\begin{array}{ll}\text { 1. } & \text { Screening } \\
\text { 2. } & \text { Scoping } \\
\text { 3. } & \text { Assessing } \\
\text { 4. } & \text { Recommending } \\
\text { 5. } & \text { Reporting } \\
\text { 6. } & \text { Monitoring and Evaluating }\end{array}$ \\
\hline Conditions for use & $\begin{array}{l}\text { Inform the drafting or revision of policy and } \\
\text { influence policy implementation to consider social, } \\
\text { economic, and environmental causes of health. }\end{array}$ & $\begin{array}{l}\text { Assess the potential health impact of a proposed } \\
\text { plan, project, policy or program. } \\
\text { Develop strategies for promoting positive health } \\
\text { impacts and/or mitigating adverse health impacts } \\
\text { of the decision }\end{array}$ \\
\hline
\end{tabular}

\section{The Somerville Partnership}

We employed HLA as part of a community-based participatory research (CBPR) and action study to mitigate the negative health effects of TRAP and ultrafine particles (UFPs) in Somerville, MA. Somerville is an inner-core community abutting Boston to the northwest. It is the most densely populated city in New England with a population of over 81,000 living in 4.1 square miles [16]. Somerville has a history of hands-on community involvement in health policy development and site-specific evidence on resident air pollution exposures and health effects [17]. In 2006, local environmental health activists brought TRAP-related concerns to university stakeholders with the aim of seeking consultation on a legal case [18]. The result was an interdisciplinary community research partnership that has been collaborating on TRAP mitigation efforts for more than a decade $[19,20]$.

Community Assessment of Freeway Exposure and Health (CAFEH) is a multi-university and multi-community consortium that has generated substantial evidence of associations between TRAP and poor health [21-23]. CAFEH has focused, specifically, on the ultrafine particulate (UFP) component of TRAP. UFPs are smaller than 0.1 microns in diameter and can penetrate deep into the lungs, where they can be transferred throughout the body, impacting many organs and tissues [24]. CAFEH research demonstrated that long-term exposures to ultrafine particles were associated with biomarkers of cardiovascular disease risk in Somerville as well as in Boston Chinatown. This work was among the first to show health associations with exposure to ambient ultrafine particles [22].

Building barriers along the roadway, such as noise barriers, may reduce TRAP exposure among residents in addition to reducing traffic noise [25,26]. As such, stakeholders employed an HLA focused on noise barriers as well as additional alternatives including: remediation at the building level, such as improved weatherization and mechanical ventilation, for housing authority properties, and using landscaping and siting to reduce exposure at a neighborhood park. Although, a high concentration level of UFP in the Somerville neighborhoods bordering I-93 was established in the literature [21,23,27], we found a lack of site-specific data on traffic-related noise pollution. For that reason, the researchers partnered with community organizations to collect supplemental data on noise pollution and the health impacts of near-highway exposures; data which key stakeholders identified as critical to advocating for noise barriers as a mitigation strategy. 
In Somerville, community partners have organized around the highway and its impacts on the community for more than 30 years $[19,28]$, and much of their work has focused on advancing environmental justice (EJ).

The EJ determination is based on the principle that all people have the same right to be protected from environmental pollution and to live in and enjoy a clean and healthful environment [29]. It recognizes that lower-income groups often live in areas overburdened by environmental hazards. EJ communities are defined as U.S. Census block groups that meet one or more of the following criteria: (1) the median annual household income is at or below $65 \%$ of the statewide median income for Massachusetts; (2) $25 \%$ of the residents are racial or ethnic minorities or $25 \%$ of residents are foreign born; or (3) $25 \%$ of residents lack English language proficiency [30]. As seen in Figure 1, all three criteria are found in the area near I-93 in Somerville.

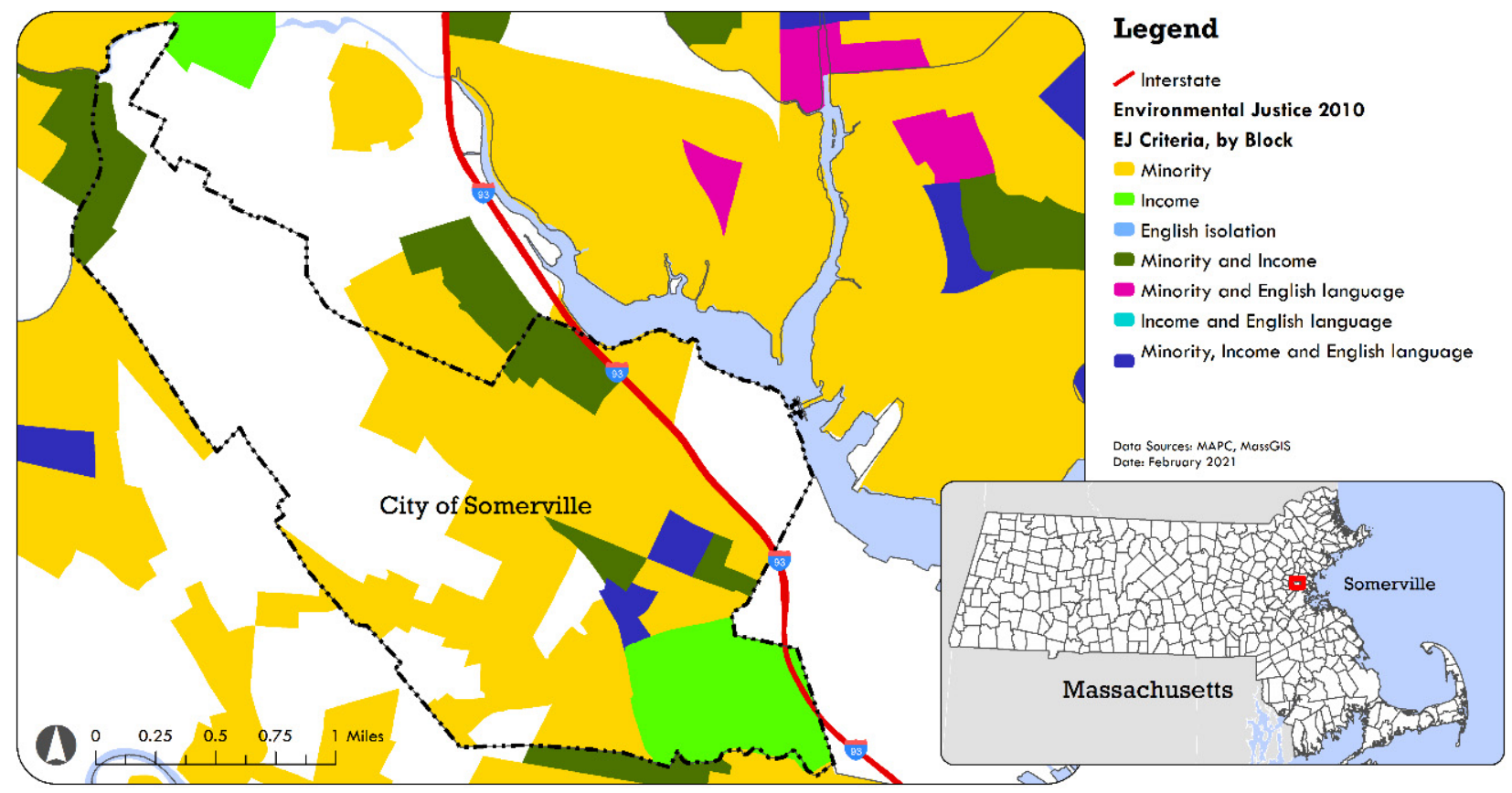

Figure 1. Environmental Justice Criteria near I-93 in Somerville, MA.

\section{Materials and Methods}

We employed the HLA framework with its five-stage process: engagement, gathering evidence, generating recommendations, navigating and evaluating [7]. These stages are iterative; once new information is gained during the HLA process, previous stages can be revisited and refined to improve policy development. As illustrated in Figure 2, we began with community engagement, which continued iteratively through the process, as new stakeholders were identified and integrated. A key stakeholder meeting informed an initial listening session. Themes from the session were prioritized and framed the development of open houses. Data from the open houses thus informed a day-long larger design charrette of the results of which were contextualized in follow-up stakeholder meetings. In this section, we describe each component of the process. 


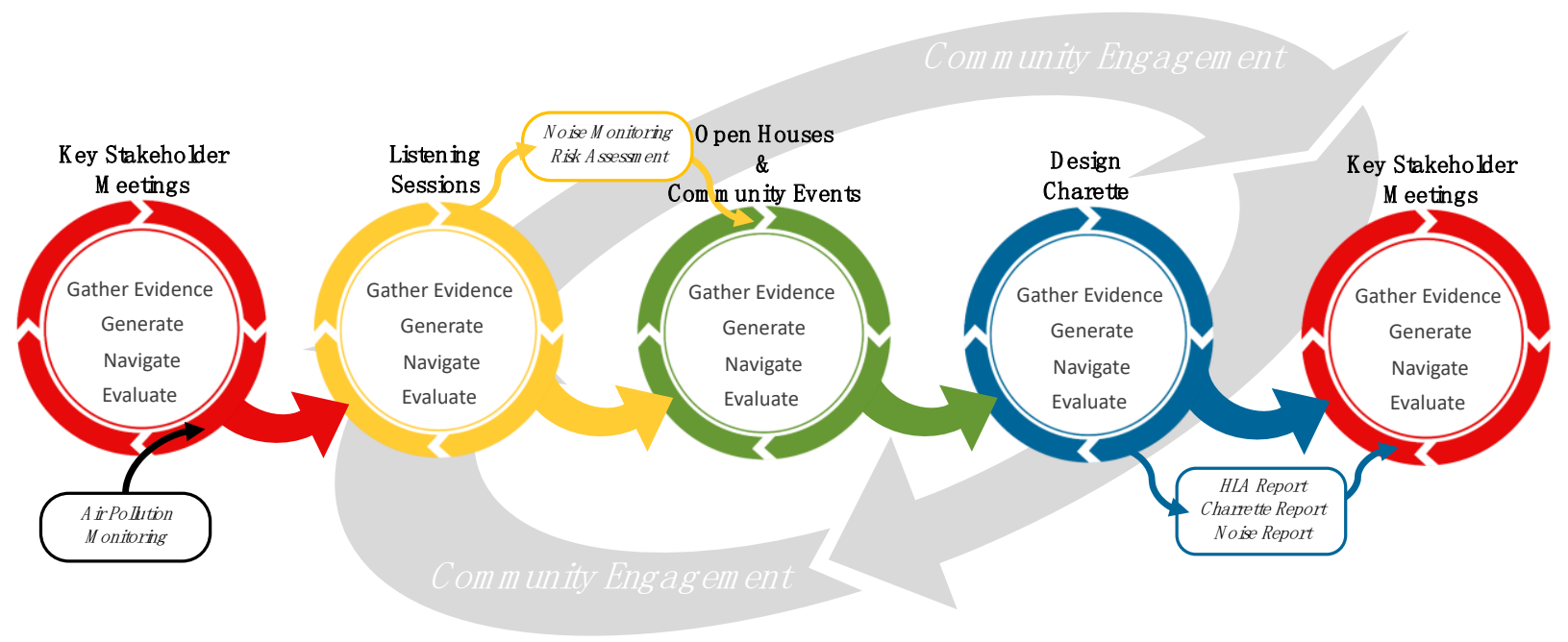

Figure 2. Somerville HLA conceptual model.

\subsection{Community Engagement}

We engaged nine key stakeholders early in the process who met together three times from November 2017 through April 2019. The nine-member stakeholder team served as an advisory board for the project team, providing coordination throughout the process and through participation in community-wide events. Members included: three Massachusetts legislative representatives and their assistants, two City of Somerville elected officials, leaders of three community-based organizations, and key municipal government staff. Early on in the process, stakeholders showed an interest in noise barriers along the highway as a strategy to divert TRAP and to reduce, not eliminate, its impact on health. Additionally, urban design and building construction, heating, ventilation, and air conditioning (HVAC) and filtration were discussed as possible strategies to mitigate TRAP.

Throughout the 18 month planning process, the team engaged residents from across the near-highway neighborhoods of Somerville in a series of activities designed to identify health concerns and generate recommendations for policies and projects to improve health. A timeline of activities can be seen in Figure 3.

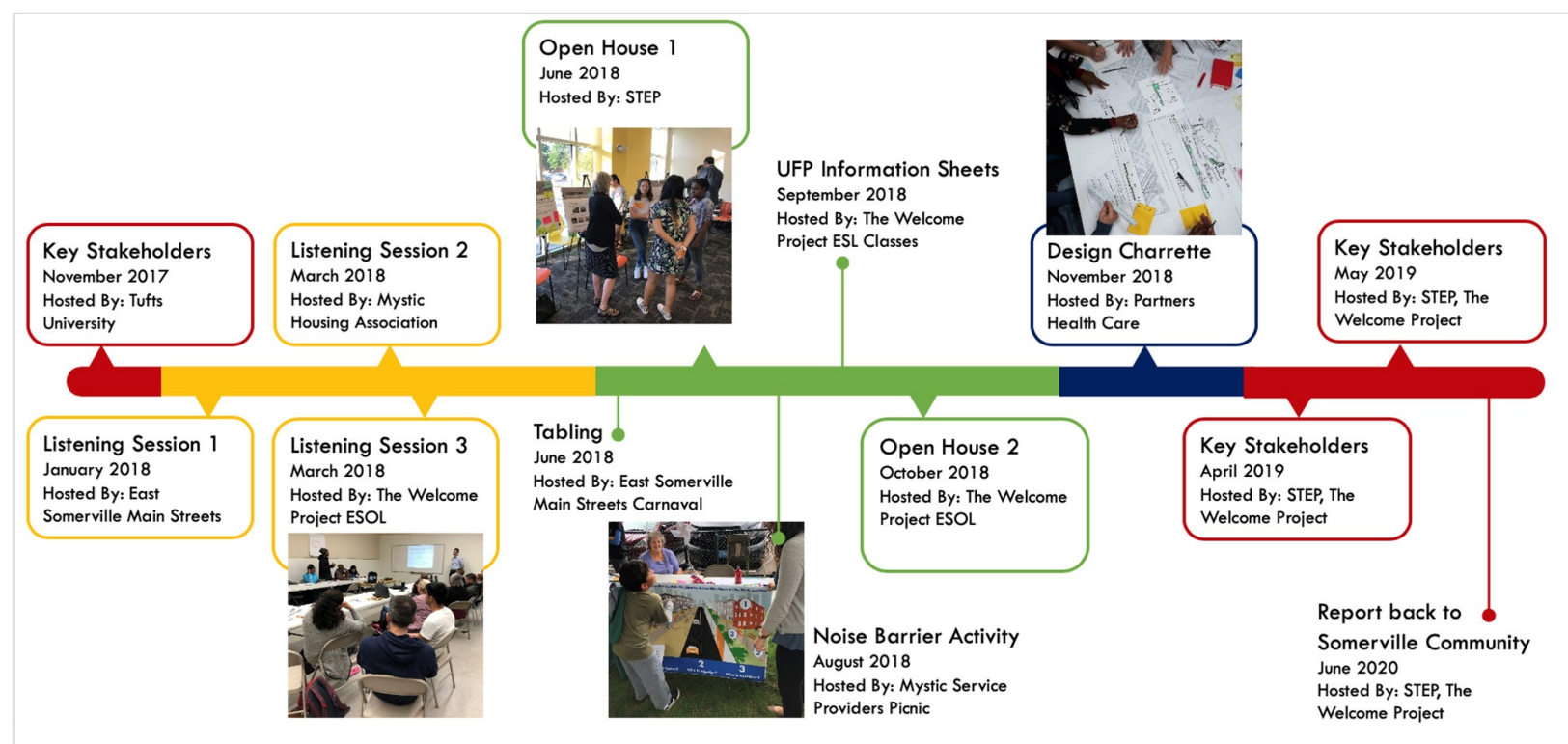

Figure 3. A Timeline of Community Engagement around HLA Planning. 
Strategies to engage residents included facilitated resident conversations, open house presentations, tabling at events, and a community participatory design charrette (an intensive, hands-on planning session), described in detail below.

Listening sessions. We held three listening sessions, facilitated discussions to collect information and experiences, with residents to identify potential linkages between installation of noise barriers along I-93 and health outcomes, vulnerable populations, and available data sources. While participants mentioned a wide range of health concerns related to the highway and noise barrier installation, air quality, noise, and quality of the parks and streetscapes in the near-highway neighborhoods surfaced as priority concerns in all three sessions.

Open houses. Project team members also hosted two open houses at community centers that used display boards to present the evidence gathered from the noise monitoring campaign and CAFEH's academic research on the effects of UFPs on the health of nearhighway residents in Somerville. Team members provided indicators of social and physical environment quality, shared a synthesis of the literature on noise barriers, and collected questions and concerns regarding noise barrier installation from the community.

Community events. Representatives from community-based organizations identified additional opportunities for project team members to participate in or present at Somerville community events including the Mystic Service Providers Picnic, East Somerville Main Streets Carnival and The Welcome Project's adult English language learner's class. The goal of these opportunities was to increase awareness and interest of community members to influence the decision-making processes.

Participatory design charrette. The HLA project culminated in a participatory design charrette, an intensive, hands-on planning session. This day-long event brought together community residents, local government staff, environmental scientists, public health experts, building and landscape architects, planners and urban designers to develop evidence-based approaches to reduce residential exposure to highway air pollution and noise and to improve the public realm.

To ensure that community residents who were most impacted by air pollution were part of the process, we sought to engage new immigrants and youth. We did this primarily through the Welcome Project's Liaison Interpreter Program of Somerville (LIPS), which trains bilingual high school students to be interpreters. The LIPS teenagers participated in and provided interpretation for all community events associated with the HLA process.

\subsection{Gathering Evidence}

We reviewed the literature to explore the efficacy of noise barriers as a UFP mitigation strategy and their role on the perceived quality of the public realm. Next, we consulted with noise barrier experts to expand upon the findings in the literature and provide additional context on the role of vegetation. We assessed quantitative data on the social determinants of health, based on recommendations from the literature and from community engagement. We prioritized publicly available data to enhance the data's relevance to community members in tracking community challenges over time and identifying opportunities for action. These findings informed the assessment and were presented to community members at two open houses and the charrette.

Mobile air pollution monitoring. CAFEH had previously conducted extensive mobile air pollution monitoring campaigns of the areas next to the highway in Somerville. CAFEH drove a converted recreational vehicle, outfitted with multiple air pollution monitoring instruments, along a predetermined route through the area. The route was systematically collected over the course of a year to gain an understanding of how pollutant concentrations varied due to traffic conditions, geographic location and weather [17].

Noise monitoring study. This study was conducted by community partners and researchers working with residents and business owners to host noise monitors at their properties over an 8 week period, from June to August 2018. We plotted the collected data in order to compare the hours when noise exceeded recommended noise exposure 
thresholds and to assess the need for and efficacy of I-93 noise barriers. We published the methods and findings in a noise monitoring report, which found that peak hour noise measurements exceeded the recommended thresholds at all study sites except for the site furthest away from the highway corridor, which confirmed that excessive traffic noise impacts the study area [31].

Risk Assessment of Exposures. We conducted a preliminary risk assessment to estimate the combined impact of air and noise pollution - the two identified health impacts of concern. Researchers applied risk estimates drawn from the literature to the population living within $400 \mathrm{~m}$ of the highway in Somerville. Results estimated the new cases of coronary heart disease, death from coronary heart disease, ischemic stroke, post-stroke mortality, type-two diabetes, lung cancer, childhood asthma, and childhood autism over a 5 -year period due to exposure to freeway air pollution. For example, childhood asthma increased by $83 \%$ among people living $50 \mathrm{~m}$ from the highway, while type- 2 diabetes increased by $81 \%$, lung cancer increased by $60 \%$, and death by heart failure increased by $54 \%$, all for people living $100 \mathrm{~m}$ or less from the highway [32].

\subsection{Generating Recommendations}

Borrowing from methods previously used in design charrette events organized by CAFEH [33], participants with diverse expertise gathered in teams of 6-10 with a design facilitator to brainstorm design ideas that would remediate noise and TRAP in the study areas. Participants' ideas were captured in notes and with sketches over design plans, cross sections and perspectives. Two design sessions were held during the all-day charrette. Participant notes and drawings formed the foundation of the recommendations that emerged from the HLA. We published a separate charrette report to document the ideas proposed during the event in a graphic and easily accessible format [34]. Ideas varied by location. As seen in Figure 4, resulting designs from the charrette report included, from left to right, the clear glass and vegetated noise barrier designs preferred by participants, use of recreational structures-like climbing walls-as barriers, and recommendations for building-level remediation needed for near-highway homes in areas not suitable for noise barrier installation.

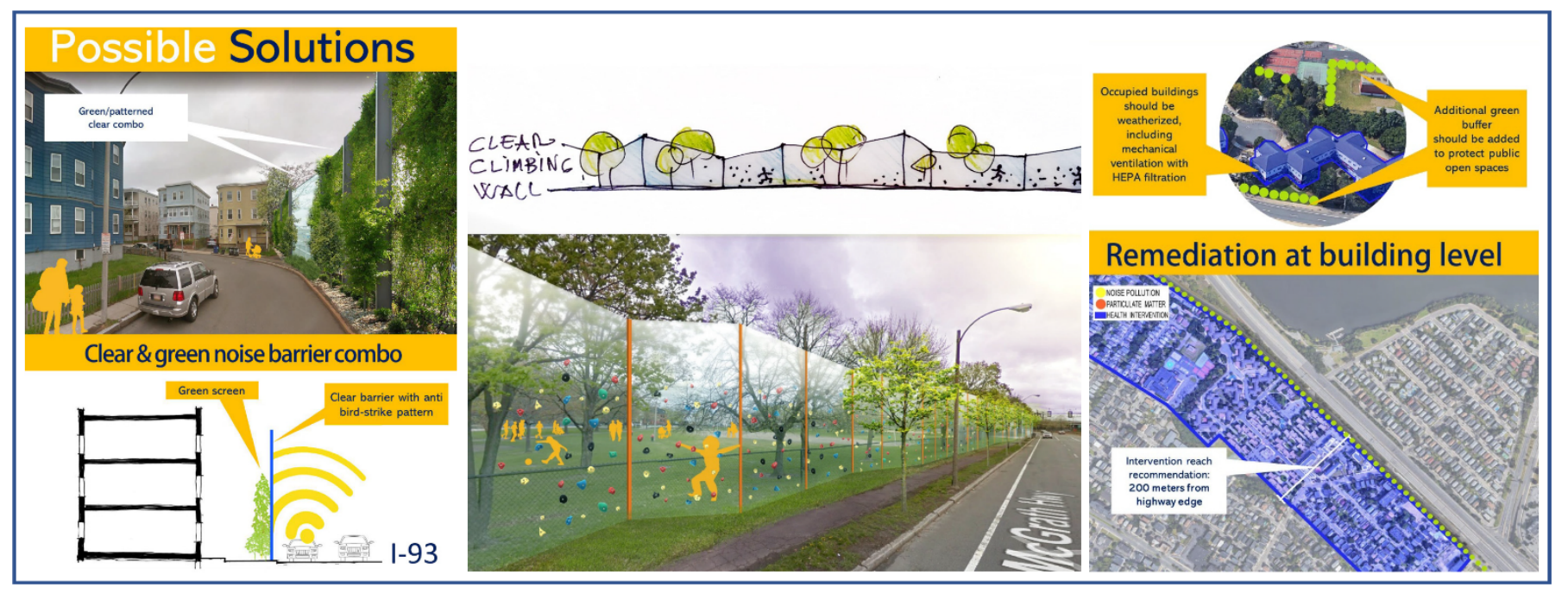

Figure 4. Resulting Designs from Charrette.

\subsection{Navigating}

We conducted our Health Lens Analysis (HLA) with the goal of bringing community stakeholders and researchers together around air pollution to develop and examine possible protective measures. Noise barrier installation along the Somerville stretch of I-93 was an intervention of particular interest for the community. However, the Massachusetts 
Department of Transportation (MassDOT) process for choosing sites does not prioritize noise barrier installation I-93 in Somerville.

For existing highways, MassDOT considers installation of noise barriers only if there is substantial alteration or if the highway is on the statewide Noise Barrier Priority List, populated based on a 1988 statewide noise study and not updated since. Despite acknowledgement by the Environmental Protection Agency (EPA) of the benefits of sound barriers to reduce pollution exposure, as well as evidence of the multiple dangers of particulate and vehicular air-toxic emissions, TRAP is not a factor for construction of sound barriers in MassDOT and federal DOT policy [35].

Thus, we focused on raising awareness of noise barriers as a possible long-term solution in outreach to state legislators and MassDOT staff, while gathering evidence which could influence more immediate policy and development discussions.

\subsection{Evaluating}

Evaluating involves "determining the effectiveness of the health lens" [7]. Community meetings were observed and stakeholders were asked to provide feedback on a form. After each session, the planning team met to reflect on the process associated with each session as well as attendance and participant engagement at each session. In addition, a project evaluator provided a report back for the group to reflect on. Themes that emerged from sessions were synthesized by the group and used to inform each subsequent session.

\section{Results}

Health Lens Analysis (HLA) proved to be an effective process through which to explore community interests and residents' concerns about living near a busy highway and collaboratively develop long-term goals, while working with key stakeholders to capitalize on available policy and re/development opportunities. We identified three key themes, described below, which capture the outcomes of community engagement, gathering evidence, and navigating recommendations.

\subsection{Role of Community Engagement in Defining HLA Scope}

The "engage" step, during which the project's scope and focus were determined, was lengthy but fundamental to project success. Table 2 describes the engagement events we organized to gauge stakeholder and resident concerns and interests by event. Registration provides evidence of sustained interest from a diverse group of residents and key stakeholders. With the exception of city staff, each key stakeholder attended at least one listening session and one open house. There was some overlap of participants between meetings; ten participants attended multiple events, with two residents attending three or more.

Table 2. Community Engagement Activity and Number of Registered Participants.

\begin{tabular}{cc}
\hline Engagement Event & Participants \\
\hline Listening Session 1 & $n=40$ \\
Listening Session 2 & $n=25$ \\
Listening Session 3 & $n=21$ \\
Open House 1 & $n=21$ \\
Open House 2 & $n=22$ \\
Design Charette & $n=56$ \\
\hline
\end{tabular}

Residents who participated in the project raised a wide range of health concerns related to the proximity of I-93, yet air quality and noise pollution were consistently mentioned as priorities.

With respect to the proposed noise barrier solution, we found that participants were interested in barrier aesthetics as well as function. Residents reported that a noise barrier, as a visual reminder that the highway was being buffered, may improve their sense of 
well-being, but that an unadorned barrier could be harsher than looking at the highway. There was a clear preference for solutions that increased greenery for the near-highway communities. In response, the project team sought consultation with a noise barrier subject-matter expert to provide additional context on the role of vegetation as barriers and barriers with vegetation covering. Further, although the site and metrological conditions of Somerville would make effective vegetation-only barriers impractical [36], there is evidence that combined vegetated and solid noise barriers may reduce air pollution more than either barrier alone [37].

\subsection{Gathered Evidence of the Impact of I-93 on Resident Health and Well-Being}

The process of describing and, where possible, quantitatively estimating, the links between I-93 and resident health and well-being was critical to motivating and providing support for considering proposed mitigation strategies. This occurred primarily in the "gathering evidence" step of the HLA.

A site-specific predictive model of UFP effectively illustrated the high levels of UFP adjacent to I-93 and along Broadway, a local commercial corridor located in Somerville [38]. Related research also found that Somerville residents with higher exposure to UFP tend to have higher levels of inflammation in their blood [22]. Furthermore, the noise-monitoring study conducted in support of our HLA found that noise was elevated near I-93, which, in turn, would be expected to impact health outcomes. With a single more remote exception, we found that sound levels exceeded both government residential and health-based sound thresholds at all sites monitored in the near I-93 neighborhoods [31]. The highway-related exposure risk assessment provided estimated cases of each health outcome over 5 years for Somerville's near-highway population. Estimates are consistent with negative health outcomes in both adults and children [32].

By demonstrating how noise barriers along I-93 could effectively reduce residents' exposure to pollutants, the HLA also raised awareness of the high levels of pollutants in the area. Based on evidence from both local research and the broader literature, we anticipate that noise barriers would reduce resident exposure to air and noise pollution along I-93 in Somerville [36,37]. Together with consideration of aesthetics, barriers could also significantly improve the quality of the public realm. While overall viable, geographic and metrological conditions may limit barrier installation and efficacy in certain locations in Somerville. Wind direction relative to the highway, places where the highway is on a berm with heavy street traffic at its base, and presence of cross streets, are limiting factors for one section of the highway through Somerville [36]. We illustrated the way neighborhood conditions and health outcomes may be impacted by the installation of noise barriers (Figure 5). 


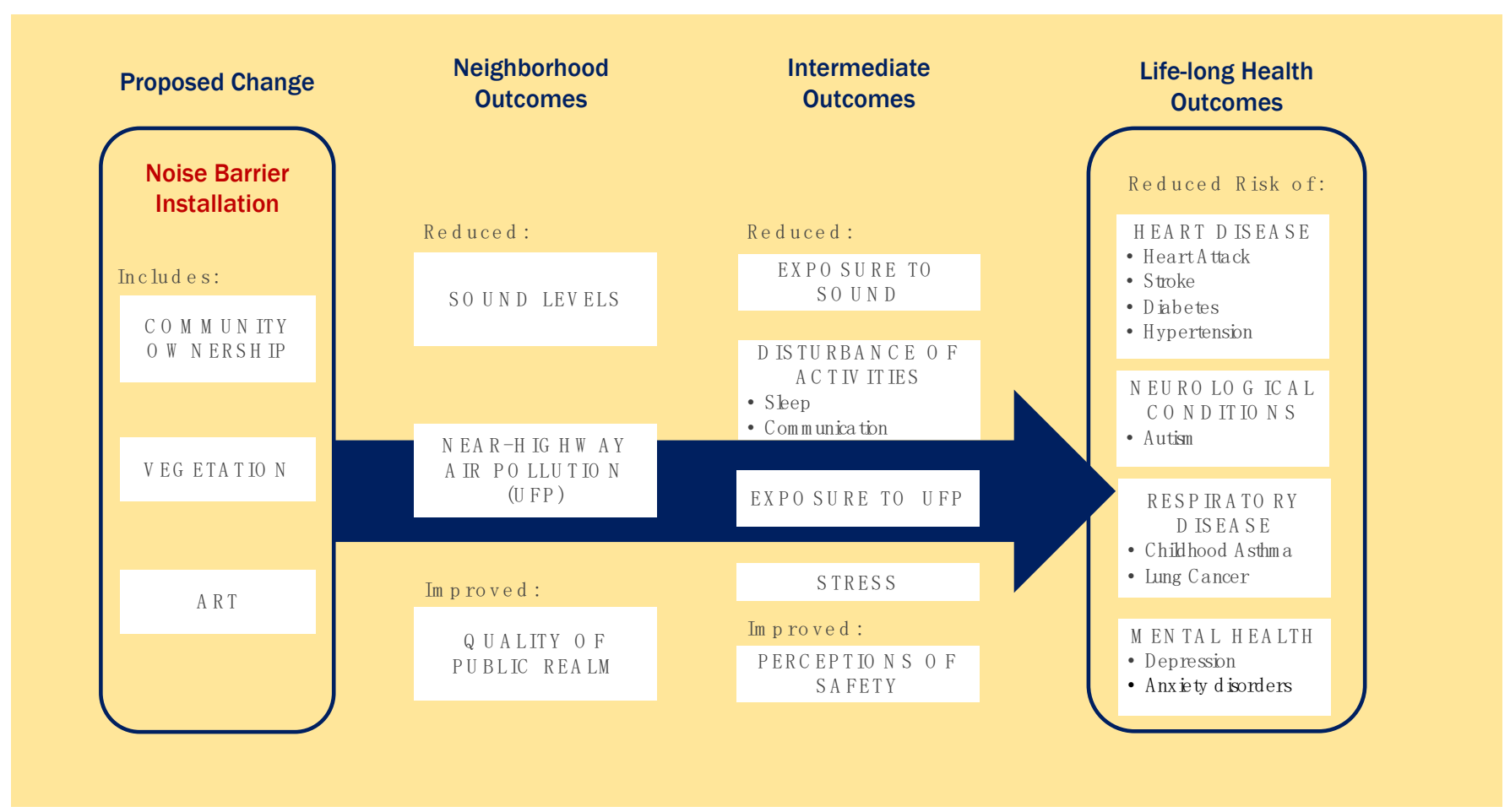

Figure 5. Changes in Neighborhood Conditions as a Result of Noise Barrier Installation.

\subsection{Navigating Recommendations to Inform Policy-and Decision-Making}

Subsequent to our HLA, State Representatives secured $\$ 65,000$ in the FY18 budget to address air and noise pollution locally. In part influenced by our HLA, the funds were allocated to the Massachusetts Department of Transportation (MassDOT) to conduct its own noise monitoring study. Our project team members met with MassDOT and their consultants to help inform their sampling protocol, locations, and parameters. Their findings were published as a monograph in 2020 and were consistent with our noise monitoring study [38]. Subsequently, STEP (the Somerville Transportation Equity Partnership) has continued to advocate, beyond conclusion of the HLA, for noise barriers for the Somerville stretch of I-93. Further, STEP has engaged with the Somerville legislative delegation to include funding for sound barriers in the statewide transportation bond bill.

At the city level, The Welcome Project (TWP) shared the recommendations from our charrette with the City of Somerville and was invited to facilitate a community meeting about redesign of a park next to the highway. This resulted in a coalition submitting a petition to the City inclusive of HLA recommendations to improve air and noise pollution quality at the site [39]. Project partners have also worked with City Councilors to ask the Board of Health (BoH) and Somerville's Office of Strategic Planning and Community Development (OSPCD) to explore opportunities to provide guidance around air pollution mitigation measures, such as a building level [40].

\section{Discussion}

Our experience is evidence that HLAs can provide an inclusive process in EJ communities, enabling the voices of marginalized residents to influence developing an agenda for their community. Interpreters were available at open houses, listening sessions, and the design charrette and community partners conducted focused, multilingual outreach to publicize these events. Despite these efforts, attendance from non-English speaking residents was limited at the events. The project team achieved greater success, bringing presentations to meetings/spaces where these residents already were, such as English as a Second Language (ESOL) classes at The Welcome Project, and Mystic Resident Association meetings. 
The HLA was an effective means to engage a multi-sectoral project team, a diverse group of stakeholders, and the community in a discussion about the health impacts of near-roadway exposures. The iterative process allowed the project team to explore fully the arguments for noise barriers, while building a base that was interested in noise and air pollution, thus creating a shared language and understanding of the issue. The HLA methods were flexible enough to allow for creative solutions that could take advantage of emerging opportunities to influence policy and other planning processes.

Agenda setting was an important outcome of this work. While the HLA is over, the discussion and advocacy that draws on the HLA has continued. Through this planning process, project partners have built relationships that have advanced public discussion of noise barriers (see: MassDOT noise study and State Bond Bill) and drawn attention to this issue in other planning processes (see: park redesign including air pollution considerations), including re-energizing key stakeholder leadership (see: City Councilors, BoH and Planning department conversations around how air pollution can be regulated as well as developing approaches for providing guidance at the local government level). Key stakeholders continue to address the challenges of reducing exposure to TRAP and noise pollution for residents living near I-93 through education, advocacy and ongoing research.

The use of HLA in this community project demonstrated the potential for collaboration between academic, government, and community partners to use this approach to develop a community agenda about TRAP. Thus, we would argue that this paper presents an illustrative example of how an HLA was employed in Somerville, MA, and highlights the benefits of adopting HLA as a tool that can contribute to community planning. Our experience demonstrates the potential to use HLAs as a strategy that includes residents and stakeholders in collective decision-making in EJ communities like Somerville.

While HLAs are less well known than HIAs, we found that HLA was a good fit for our process in several important ways. First, not all communities have the infrastructure and resources in place for the robust quantitative and qualitative data assessment HIA requires. Second, unlike the HIA process, the HLA does not require a preexisting proposal as a guideline.

The constraints of the MassDOT sound barrier program were a substantial challenge to the CAFEH team, because it does not have a process to consider noise barriers installation along I-93 in Somerville, nor does it acknowledge the benefits of sound barriers to reduce pollution exposure. Further, site constraints and environmental conditions are barriers to making all locations along I-93 equally strong candidates for hosting noise barriers. As such, the HLA process and outcomes might, instead, influence decision-makers to include air pollution when making a variety of planning and policy interventions in the area.

In summary, the HLA proved to be a useful tool for encouraging alternative decisionmaking related to air pollution. Moreover, the format we used allowed us to engage diverse community stakeholders and to deepen our engagement with them through each component of the HLA. This model provides a useful framework for implementing HLA in a North American context.

Author Contributions: S.R.: conceptualization, writing-original draft, validation. N.D.: methodology, formal analysis, writing — original draft. S.L.G.: formal analysis, writing-original draft, review and editing. E.R.: supervision, conceptualization, project administration, writing-review and editing, validation. P.B.M.: methodology, writing-review and editing. W.Z.: conceptualization, writing - review and editing, validation. B.E.: methodology, writing-review and editing. D.B.: conceptualization, supervision, project administration, funding acquisition. L.S.S.M.: conceptualization, supervision, methodology, formal analysis, writing—original draft. All authors have read and agreed to the published version of the manuscript.

Funding: This study was funded by the National Institute of Environmental Health Sciences, Grant title: Near Highway Pollution: From Research to Action (R01ES026980) and Grant title: Home Air Filtration for Traffic-Related Air Pollution (R01ES030289). 
Institutional Review Board Statement: The study was conducted according to the guidelines of the Declaration of Helsinki, and approved by the Institutional Review Board of Boston University (protocol \#4434X) on 17 March 2017.

Informed Consent Statement: The study was determined to be exempt. Written consent was waived. A consent script was reviewed with participant and documented by the evaluator.

Data Availability Statement: Data are contained within the article. No new datasets were created for this article.

Acknowledgments: We thank the many people who contributed to this work, including faculty, students, community partners and members, staff and volunteers, including Minyu Szeto, who assisted with the literature search. In particular, we would also like to thank the authors of the CAFEH Noise Barrier Report [38] for their incredible work, which laid the groundwork for this paper.

Conflicts of Interest: The authors declare that they have no conflict of interest.

\section{References}

1. Corburn, J.; Curl, S.; Arredondo, G.; Malagon, J. Health in All Urban Policy: City services through the prism of health. J. Urban Health 2014, 91, 623. [CrossRef] [PubMed]

2. Melkas, T. Health in all policies as a priority in Finnish health policy: A case study on national health policy development. Scand. J. Public Health 2013, 41. [CrossRef]

3. Centers for Disease Control and Prevention. Health in All Policies. 2016. Available online: https://www.cdc.gov/policy/hiap/ index.html (accessed on 10 June 2020).

4. Gugliemin, M.; Muntaner, C.; O'Campo, P.; Shankardass, K. A scoping review of the implementation of health in all policies at the local level. Health Policy 2018, 122, 284-292. [CrossRef]

5. Ollila, E. Health in All Policies: From rhetoric to action. Scand. J. Public Health 2011, 39, 11-18. [CrossRef] [PubMed]

6. Puska, P.; Ståhl, T. Health in All Policies-The Finnish Initiative: Background, Principles, and Current Issues. Annu. Rev. Public Health 2010, 31, 315-328. [CrossRef] [PubMed]

7. Government of South Australia, Department of Health. "Health Lens Analysis Projects". Version 2. 2011. Available online: https: / / www.sahealth.sa.gov.au/wps/wcm/connect/public+content/sa+health+internet/about+us/about+sa+health/health+in+ all+policies / health+lens+analysis+projects / health+lens+analysis+projects\#: \{\}:text=The\%20Health\%20Lens \%20Analysis\%20 (accessed on 29 September 2020).

8. Van Eyk, H.; Harris, E.; Baum, F.; Delany-Crowe, T.; Lawless, A.; MacDougall, C. Health in all policies in South Australia-did it promote and enact an equity perspective? Int. J. Environ. Res. Public Health 2017, 14, 1288. [CrossRef] [PubMed]

9. Lawless, A.; Williams, C.; Hurley, C.; Wildgoose, D.; Sawford, A.; Kickbusch, I. Health in All Policies: Evaluating the South Australian approach to intersectoral action for health. Can. J. Public Health 2012, 103, S15-S19. [CrossRef]

10. Newman, L.; Ludford, I.; Williams, C.; Herriot, M. Applying health in all policies to obesity in South Australia. Health Promot. Int. 2016, 31, 44-58. [CrossRef]

11. Metropolitan Area Planning Council. Health Lens Analysis of Urban Agriculture Policy, Cambridge, MA. 2019. Available online: http:/ /www.mapc.org/wp-content/uploads/2019/04/Cambridge-Health-Lens-Analysis_FINAL.pdf (accessed on 14 January 2021).

12. Cambridge Public Health Department. Cambridge Urban Agriculture: A Guide to Beekeeping, Community Gardening, \& More in the City. 2019. Available online: https://www.cambridgema.gov/ \{\}/media/Files/CDD/Planning/urbanagriculture/ urbanagguidefinal.pdf (accessed on 14 January 2021).

13. Gase, L.; Schooley, T.; Lee, M.; Rotakhina, S.; Vick, J.; Caplan, J. A Practice-Grounded Approach for Evaluating Health in All Policies Initiatives in the United States. J. Public Health Policy Manag. 2017, 23, 339-347. [CrossRef]

14. Mueller, M.; Rojas-Rueda, D.; Cole-Hunter, T.; de Nazelle, A.; Dons, E.; Gerike, R.; Götschi, T.; Int Panis, L.; Kahlmeier, S.; Nieuwenjuijsen, M. Health impact analysis of active transportation: A systematic review. Prev. Med. 2015, 103-114. [CrossRef]

15. Delany, T.; Harris, P.; Williams, C.; Harris, E.; Baum, F.; Lawless, A.; Wildgoose, D.; Haigh, F.; MacDougall, C.; Broderick, D.; et al. Health impact assessment in new South Wales \& Health in all policies in South Australia: Differences, similarities and connections. BMC Public Health 2014, 14, 699. [CrossRef]

16. United States Census Bureau. QuickFacts: Somerville, Massachusetts. 2019. Available online: https://www.census.gov/ quickfacts/somervillecitymassachusetts (accessed on 23 October 2020).

17. Padró-Martínez, L.T.; Patton, A.P.; Trull, J.B.; Zamore, W.; Brugge, D.; Durant, J.L. Mobile monitoring of particle number concentration and other traffic-related air pollutants in a near-highway neighborhood over the course of a year. Atmos. Environ. 2012, 61, 253. [CrossRef] [PubMed]

18. Martínez, L.S.; Reisner, E.; Campbell, M.; Brugge, D. Participatory Democracy, Community Organizing, and the Community Assessment of Freeway Exposure and Health (CAFEH) Partnership. Int. J. Environ. Res. Public Health 2017, 14, 149. [CrossRef] [PubMed] 
19. Martinez, L.S.S.; Dimitri, N.; Ron, S.; Hudda, N.; Zamore, W.; Lowe, L.; Echevarria, B.; Durant, J.L.; Brugge, D.; Reisner, E. Two communities, one highway, and the fight for clean air: The role of political history in shaping community engagement and environmental health research translation. BMC Public Health 2020, 1690. [CrossRef]

20. Martinez, L.S.S.; Zamore, W.; Finley, A.; Reisner, E.; Lowe, L.; Brugge, D. CBPR Partnerships and Near-Roadway Pollution: A Promising Strategy to Influence the Translation of Research into Practice. Environments 2020, 7, 44. [CrossRef]

21. Corlin, L.; Woodin, M.; Hart, J.E.; Simon, M.C.; Gute, D.M.; Stowell, J.; Tucker, K.L.; Durant, J.L.; Brugge, D. Longitudinal Associations of Long-Term Exposure to Ultrafine Particles with Blood Pressure and Systemic Inflammation in Puerto Rican Adults. Environ. Health 2018, 17, 33. [CrossRef]

22. Lane, K.J.; Levy, J.I.; Scammell, M.K.; Patton, A.P.; Durant, J.L.; Mwamburi, M.; Zamore, W.; Brugge, D. Effect of time-activity adjustment on exposure assessment for traffic-related ultrafine particles. J. Expo. Sci. Environ. Epid. 2015, 25, 506. [CrossRef]

23. Li, Y.; Lane, K.J.; Corlin, L.; Patton, A.P.; Durant, J.; Thanikachalam, M.; Woodin, M.; Wang, M.; Brugge, D. Association of Long-Term Near-Highway Exposure to Ultrafine Particles with Cardiovascular Diseases, Diabetes and Hyperextension. Int. J. Environ. Res. Public Health 2017, 14, 461. [CrossRef]

24. Maher, B.A.; Ahmed, I.A.M.; Karloukovski, V.; MacLaren, D.A.; Foulds, P.G.; Allsop, D.; Mann, D.M.; Torres-Jardón, R.; Calderon-Garciduenas, L. Magnetite pollution nanoparticles in the human brain. Proc. Natl. Acad. Sci. USA 2016, $113,10797$. [CrossRef]

25. Botana, P.; CAFEH Team. Design Charrette: Designing a Healthier Community. 2019. Available online: https://cafeh.squarespace. $\mathrm{com} / \mathrm{s} /$ Somerville-Design-Charrette (accessed on 2 November 2020).

26. Bowlby, W.; Pratt, G.; Williamson, R.L.; Knauer, H.S.; Kaliski, K. Noise Barrier Acceptance Criteria: Analysis; (No. FHWA-HEP-16017); Federal Highway Administration: Washington, DC, USA, 2015.

27. Hassen, N.; Kaufman, P. Examening the role of urban street design in enhancing community engagement. Health Place 2016, 41, 119-132. [CrossRef]

28. Beaton, M.A. Environmental Justice Policy of the Executive Office of Energy and Environmental Affairs, Commonwealth of Massachusetts. 2017. Available online: https://www.mass.gov/files/documents/2017/11/29/2017-environmental-justicepolicy_0.pdf (accessed on 14 January 2021).

29. Cole, L.W.; Foster, S.R. From the Ground Up: Environmental Racism and the Rise of the Environmental Justice Movement; New York University Press: New York, NY, USA, 2001.

30. Constitution of the Commonwealth of Massachusetts. Environmental Justice Policy of the Executive Office of Energy and Environmental Affairs; Article 97. Signed by Matthew A. Beaton, Secretary for Energy and Environmental Affairs; Commonwealth of Massachusetts: Boston, MA, USA, 2017.

31. Leaffer, D.; Reisner, E.; Wang, G.; Zamore, W.; Chen, D.; Hudda, N.; Brugge, D. Noise Impacts in Somerville: A Noise Report. 2018. Available online: https://cafeh.squarespace.com/s/Somerville_Noise_Impact_Report.pdf (accessed on 23 October 2020).

32. Eliasziw, M. Estimates of Excess Risk and Number of New Cases Among Somerville Residents Living within 400 Meters of a Freeway over a 5-Year Period due to Exposure of Freeway Air Pollution. 2019. Available online: https://sites.tufts.edu/cafeh/ files/2019/02/00.HIA-for-R2A-Risk-Analysis-and-Estimates.pdf (accessed on 29 September 2020).

33. Brugge, D.; Patton, A.P.; Bob, A.; Reisner, E.; Lowe, L.; Bright, O.-J.M.; Durant, J.L.; Newman, J.; Zamore, W. Developing policy and practice to reduce traffic-related air pollution exposure. Environ. Justice 2015, 8, 95. [CrossRef] [PubMed]

34. Baldauf, R. Roadside Vegetation Design to Improve Local, Near-Road Air Quality. Transp. Res. Part D Transp. Environ. 2017, 11, 354. [CrossRef]

35. Baldauf, R. Recommendations for Constructing Roadside Vegetation Barriers to Improve Near-Road Air Quality. U.S. Environmental Protection Agency, Office of Research and Development, 2016. Available online: https://www.epa.gov/sites/ production/files/2016-08/documents / recommendations_for_constructing_roadside_vegetation_barriers_to_improve_nearroad_air_quality.pdf (accessed on 10 September 2020).

36. Patton, A.P.; Perkins, J.; Zamore, W.; Levy, J.I.; Brugge, D.; Durant, J.L. Spatial and temporal differences in traffic-related air pollution in three urban neighborhoods near an interstate highway. Atmos. Environ. 2014, 99, 309. [CrossRef] [PubMed]

37. Brugge, D.; Ron, S.; Reisner, E.; Botana, P.; Leaffer, D.; Zamore, W.; Martinez, L.S.; Keppard, B. Noise Barriers in Somerville: A Health Lens Analysis. Environ. Epidemiol. 2019, 3, 44. [CrossRef]

38. Community Assessment of Freeway Exposure and Health (CAFEH). Noise Barriers in Somerville: A Health Lens Analysis; Tufts University: Boston, MA, USA, 2019.

39. Foss Park Community Concerns. 2018. Available online: http:/ / somervillecityma.iqm2.com $/$ Citizens / FileOpen.aspx?Type=4\& ID=11895\&MeetingID=2991 (accessed on 14 January 2021).

40. Kress, D. City of Somerville, Masssachusetts, Health and Human Services Department: Memorandum and Agenda. 2019. Available online: https://www.somervillema.gov/sites/default/files/BOH\%20Agenda\%2009.17.19.pdf (accessed on 14 January 2021). 